\title{
Intraregional variability in chironomid-inferred temperature estimates and the influence of river inundations on lacustrine chironomid assemblages
}

\author{
S. Engels · S. J. P. Bohncke $\cdot$ O. Heiri • \\ M. Nyman
}

Received: 30 May 2007/ Accepted: 3 August 2007/Published online: 2 October 2007

(C) Springer Science+Business Media B.V. 2007

\begin{abstract}
Floodplain lakes are rarely analysed for fossil chironomids and usually not incorporated in modern chironomid-climate calibration datasets because of the potential complex hydrological processes that could result from flooding of the lakes. In order to investigate this potential influence of river inundations on fossil chironomid assemblages, 13 regularly inundated lakes and 20 lakes isolated from riverine influence were sampled and their surface sediments analysed for subfossil chironomid assemblages. The physical and chemical settings of all lakes were similar, although the variation in the environmental variables was higher in the lakes isolated from riverine influence. Chironomid concentration and taxon richness show significant differences between the two classes of lakes, and the variation in these
\end{abstract}

S. Engels $(\varangle)$. S. J. P. Bohncke

Department of Paleoclimatology and Geomorphology, Faculty of Earth and Life Sciences, Vrije Universiteit, De Boelelaan 1085, 1081 HV Amsterdam,

The Netherlands

e-mail: stefan.engels@falw.vu.nl

O. Heiri

Palaeoecology, Laboratory of Palaeobotany and Palynology, Institute of Environmental Biology, Utrecht University, Budapestlaan 4, 3584 CD Utrecht, The Netherlands

M. Nyman

Department of Biological and Environmental Sciences, Aquatic Sciences, University of Helsinki, P. O. Box 65, Viikinkaari 00014, Finland variables is best explained by loss-on-ignition of the sediments (LOI). Relative chironomid abundances show some differences between the two groups of lakes, with several chironomid taxa occurring preferentially in one of the two lake-types. The variability in chironomid assemblages is also best explained by LOI. Application of a chironomid-temperature inference model shows that both types of lakes reconstruct July air temperatures that are equal to, or slightly underestimating, the measured temperature of the region. We conclude that, although there are some differences between the chironomid assemblages of floodplain lakes and of isolated lakes, these differences do not have a major effect on chironomid-based temperature reconstruction.

Keywords Chironomids - River inundation · Floodplain - Temperature inference .

Finland

\section{Introduction}

The Chironomidae (Insecta: Diptera) is a very diverse family of aquatic insects, occurring in a multitude of habitats, and chironomids are frequently among the most abundant invertebrates found in lakes and rivers (e.g., Armitage 1995; Cranston 1995). Chironomids have been used in palaeoecological studies as a proxy for a range of different environmental variables. For instance, Gandouin et al. (2006, 2007) explored the 
ratio between lotic and lentic chironomid taxa as a tool to qualitatively reconstruct flow-regimes in dead branches of two French rivers (Rhône and Garonne). Other research projects used fossil chironomid assemblages in lake sediments to quantitatively infer past changes in July air temperature (e.g., Heiri and Lotter 2005; Brooks 2006; Walker and Cwynar 2006), salinity (e.g., Heinrichs and Walker 2006; Eggermont et al. 2006), or trophic conditions in lakes (Lotter et al. 1998; Brooks et al. 2001).

Chironomid-based temperature reconstruction has received increasing attention in recent years and a large number of chironomid-based July air temperature records are now available from formerly glaciated regions in Europe and North America (e.g., Walker et al. 1991; Brooks and Birks 2001). However, lacustrine sediments deposited in floodplain environments such as palaeochannels and oxbow lakes have to our knowledge not previously been used for quantitative temperature reconstruction based on fossil chironomids.

Floodplain sediments have great potential for chironomid-based temperature reconstructions. They can be found in landscapes beyond the maximum extent of late Quaternary glaciations (Gandouin et al. 2005; 2006) and in time windows for which other lacustrine sediment records are rare. For example, in the opencast lignite mines in eastern Germany, lacustrine sediments dating back to Oxygen Isotope Stage (OIS) - 5a and early OIS-3 (ca. 80 and $55 \mathrm{ka}$ $\mathrm{BP}$, respectively) have been retrieved (e.g., Mol 1997; Bos et al. 2001; Kasse et al. 2003). The fossil chironomid and botanical assemblages, together with the sedimentological record, all suggest that these palaeolakes were situated on a river floodplain.

Modern lakes, where high-discharge events of nearby rivers or streams can reach the lake, are usually not included in the modern calibration sets used to develop chironomid-temperature inference models because of the complex ecological processes that can be the result of such floods. As a consequence, lacustrine floodplain sediments potentially present non-analogue situations in respect to most modern chironomid-temperature transfer functions and it is presently unclear to what extent this influences quantitative temperature reconstructions.

Studies on modern lakes have shown that certain lakes, and their associated chironomid faunas, are sensitive recorders of small-scale climate changes whereas other lakes are less likely to respond to climate variability, depending on their (relative) location (e.g., Velle et al. 2005; Heegaard et al. 2006). Withinregion discrepancies are also recorded for down-core analysis of chironomid-assemblages and their associated inferred temperatures (e.g., Bigler et al. 2002; Korhola et al. 2002; Velle et al. 2005). Presently, it is unclear how large intraregional variability of chironomid-inferred temperature estimates can be, or whether this variability changes between floodplain lakes and lakes that are unaffected by inundations.

In this study, we investigate the differences between the physical and chemical properties of lakes on a river floodplain that are annually inundated, and lakes that are isolated from such riverine influence. The subfossil chironomid assemblages of these lakes are compared and the influence of river inundations on the chironomid concentrations, taxon richness and relative chironomid abundances is explored. The intraregional variability of chironomid-inferred temperature estimates is determined and compared for the two classes of lakes with the aim of assessing whether chironomid-temperature inference models, developed for lakes unaffected by riverine influence, can be applied to floodplain sediment records.

\section{Study area}

The 33 lakes studied in this project are all situated within a $6 \mathrm{~km}$ radius of the small town of Kaamanen, Finland $\left(69^{\circ} 06^{\prime} \mathrm{N}, 27^{\circ} 10^{\prime} \mathrm{E} ; 146 \mathrm{~m}\right.$ a.s.1.). The landscape of the region is characterised by outcrops of metamorphic rocks (granite, gneisses), interspersed with lakes, wetlands and mires. Today, the area around Kaamanen is situated in boreal forest, in which birch (Betula pubescens) and pine (Pinus sylvestris) are the most important tree species. Mean July air temperature at Kaamanen is $13.1^{\circ} \mathrm{C}$ and the annual precipitation averages $441 \mathrm{~mm}$ (over the period of 1971-2000; Drebs et al. 2002). The floodplain of the Muddusjoki river (Fig. 1), the largest river of the area, is covered in sedges and other wetland vegetation. The Muddusjoki is known to have fluctuating discharges (and water levels), the highest discharge being in May or June during the snow melt season. The average difference between the highest and the lowest monthly water level during the period of 1971-2005 was $137 \mathrm{~cm}$ (unpublished 


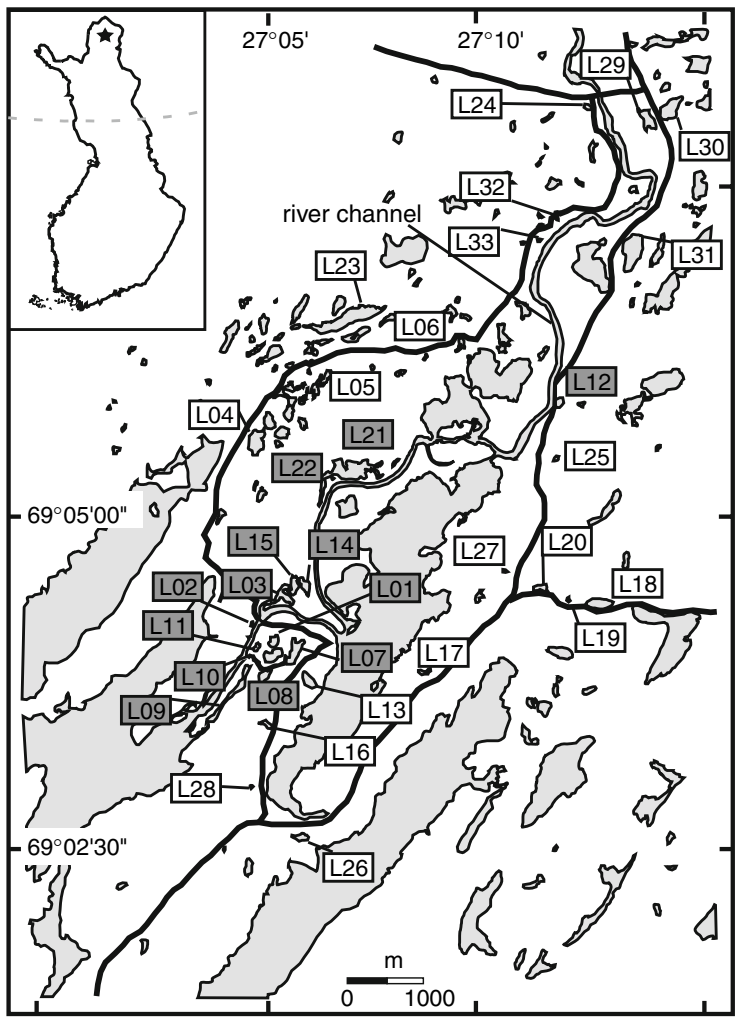

Fig. 1 Location of the 33 studied lakes in northern Finland. Inundated lakes have a shaded text box, isolated lakes a white text box. The shaded areas (light gray) represent lakes and rivers/streams

data, P. Räinä). As 13 studied lakes are situated on the same elevation as the river, they are inundated by the river during every flood. This was also evident from flood marks found during the fieldwork (e.g., evidence of erosion or debris deposits at a uniform height throughout the study area), and confirmed by local inhabitants. The other 20 lakes lie either higher or sheltered behind rock outcrops, and therefore remain isolated from riverine influence. Lake 33 differs from the other lakes in the data set as it has probably originated from the construction of a road close to the lake, and is fed by a drainage system that directs rain water away from the road and into the lake.

\section{Methods}

Fieldwork and laboratory analyses

During a 3-week fieldwork campaign in August 2006, 33 ponds and small lakes were sampled for water chemistry and surficial sediments. Vegetation, lake perimeter, number of in and outflows and possible anthropogenic influence were recorded. Lake bathymetry was established for every lake using a GPS and a water-depth gauge. At the deepest point of the lakes, water temperature, conductivity, $\mathrm{pH}$ and $\mathrm{O}_{2}$ profiles were recorded before sampling the lake sediments. Using a HON/Kajak-corer with a diameter of $6.2 \mathrm{~cm}$ (Renberg 1991), at least two cores were retrieved from every lake, and the sediment column was subsampled in $1-\mathrm{cm}$ increments in the field. The topmost one centimetre of sediment was used in this study for losson-ignition (LOI was determined following standard protocols of the Dutch Centre for Normalization at $550^{\circ} \mathrm{C}$ using a CEM MAS-300) and chironomid analysis.

Water samples were collected at $50 \mathrm{~cm}$ below the water-surface for every lake, and in the case of lakes deeper than $2 \mathrm{~m}$ or with thermal stratification, an additional water sample was retrieved from the lower part of the water column. Alkalinity of the water was measured in the field, whereas other water chemistry variables were measured in laboratories using a Dionex DX 120 Chromatograph and a Varian ICPAES. $\delta^{18} \mathrm{O}$ of the water samples was measured using a ThermoFinnigan Delta+ mass spectrometer with a GASBENCH II preparation device at a $1 \sigma$ precision of $\sim 0.1 \%$.

Subfossil chironomid remains

Prior to chironomid analysis, the sediments were freeze-dried in order to obtain a reliable estimate of chironomid concentrations per weight. Freeze-dried samples (0.019-1.818 g) were treated with cold $\mathrm{KOH}$ (10\%) for a period of at least $4 \mathrm{~h}$, before sieving over a $100 \mu \mathrm{m}$ mesh. Chironomid remains were handpicked from the residue, and mounted on permanent slides using Euparal ${ }^{\odot}$ mounting medium.

After omitting chironomid head capsules (hc) that were only identified to subfamily or tribal levels, minimum, maximum and mean count numbers per sample were 149,415 , and 184 hc respectively. Taxonomy follows Sæther (1976), Wiederholm (1983), Schmid (1993), Heiri et al. (2004) and Brooks et al. (2007). Using TILIA and TG.VIEW (Grimm 1991-2004), a chironomid abundance diagram was constructed. 
Numerical analyses

In order to compare chironomid assemblages from lakes that are regularly inundated and lakes isolated from riverine influence, a range of statistical analyses was performed, and the results are compared for the two classes of lakes.

Rarefaction analysis was performed to assess the taxon richness (TR) of the different samples. This method simulates a random selection without replacement, estimating for all samples the taxon richness for the smallest count size recorded in the entire sequence of samples. In our case, this smallest sample contained 149 identified hos, and the TR was determined for all 33 lakes for this count size using RAREPOLL (Birks and Line 1992). A t-test was performed to assess whether TR significantly differed between the two classes of lakes. In this study, 24 environmental, chemical and biological variables were determined for all 33 lakes (all variables on interval/ratio scale from Tables 1 and 2), and using redundancy analysis (RDA; Ter Braak and Looman 1994) with Monte Carlo permutation tests (unrestricted model, 999 permutations), the environmental variables that best explained the variance in TR were selected.

Chironomid concentrations were compared for the two classes of lakes using a $t$-test. Similar to the TR-analyses, RDA was performed in order to select the environmental variables that best explained the variance in chironomid concentrations. As the chironomid concentrations showed a skewed distribution, they were log-transformed prior to analysis.

The dataset containing the 24 environmental variables was subjected to a series of Principal Component Analyses (PCAs) in order to detect covariation between the different variables, and to assess differences of the chemical and physical variables between our 2 classes of lakes. Environmental variables that show a skewed distribution (i.e., all water chemistry data except for $[\mathrm{Na}],[\mathrm{K}],[\mathrm{Cl}]$ and [Ca]) were $\log$-transformed prior to the analyses. Inspection of initial results showed a high covariability between a number of variables (especially for the water chemistry data), and for subsequent PCAs redundant variables were omitted in order to create a biplot that was more readily interpretable. The omitted variables included all variables presented in Table 2, except for $\delta^{18} \mathrm{O}, \mathrm{TP},\left[\mathrm{NH}_{4}\right],\left[\mathrm{SO}_{4}\right]$ and $\left[\mathrm{PO}_{4}\right]$.
Using detrended correspondence analysis (DCA; Hill and Gauch 1980), with detrending by segments, non-linear rescaling of the axes and down-weighting of rare taxa, the amount of compositional turnover in the chironomid data was determined. As the gradient length of the first axis was 2.08 standard deviation units, the application of both unimodal and linear methods was possible in subsequent analyses (Birks 1998).

Square-root transformed percentage abundances of the chironomid taxa, with down-weighting of rare taxa, were used in a correspondence analysis (CA) to explore the distribution of the different chironomid taxa in the two lake classes. A series of direct gradient analyses (canonical correspondence analyses (CCAs)) was performed to determine the unique and marginal effects of the individual environmental variables on the variability of the chironomid abundances. The marginal effect of a given environmental variable is defined as the amount of variability in the chironomid data that would be explained by a constrained ordination model that uses this environmental variable as the only explanatory variable (Lepš and Šmilauer 2003). The unique (or conditional) effects are the partial effects of the selected variables (tested through partial Monte Carlo permutation tests), which depend on the variables already selected (Lepš and Šmilauer 2003).

A 2-component weighted averaging-partial least squares (WA-PLS) chironomid-temperature inference model was applied to the chironomid assemblages of our 33 lakes, in order to test the intraregional variability in chironomid-inferred temperature estimates, and to assess the influence of river inundation on quantitative temperature inferences. This model was based on an expanded and re-analysed training set by Olander et al. (1999) including 63 lakes in western Finnish Lapland (Vasko et al. 2000; Nyman 2007). The warmest lake in this dataset was identified as an outlier, and excluded from further analyses. The calibration data covers a mean July air temperature range of 7.9 to $14.9^{\circ} \mathrm{C}$ (1961-1990 Climate Normals data). All chironomid percentage values were square root transformed to stabilize the variance, and the model has a coefficient of determination $\left(r^{2}\right)$ of 0.75 , a root mean square error of prediction (RMSEP) of $0.76^{\circ} \mathrm{C}$, a mean bias of $0.023^{\circ} \mathrm{C}$ and a maximum bias of $1.19^{\circ} \mathrm{C}$ (all as assessed through leave-on-out cross validation). Sample specific errors were estimated through bootstrapping (999 cycles; Birks et al. 1990). 
Table 1 Physical and chemical parameters of the 33 lakes in the data set

\begin{tabular}{|c|c|c|c|c|c|c|c|c|c|c|c|c|}
\hline \multirow[t]{2}{*}{ Lake nr } & \multicolumn{5}{|c|}{ Physical parameters } & \multicolumn{5}{|c|}{ Water column } & \multicolumn{2}{|c|}{ Sediment content } \\
\hline & $\begin{array}{l}\text { Elevation } \\
\text { (m a.s.1.) }\end{array}$ & Class & $\begin{array}{l}\text { Vege- } \\
\text { tation }\end{array}$ & $\begin{array}{l}\text { Open } \\
\text { water } \\
\text { area } \\
\text { (ha) }\end{array}$ & $\begin{array}{l}\text { Water } \\
\text { depth } \\
(\mathrm{m})\end{array}$ & $\begin{array}{l}\mathrm{T} \\
\text { water } \\
\left({ }^{\circ} \mathrm{C}\right)\end{array}$ & $\mathrm{pH}$ & $\begin{array}{l}\mathrm{EC} \\
(\mu \mathrm{S} / \mathrm{cm})\end{array}$ & $\begin{array}{l}\mathrm{O}_{2} \\
(\mathrm{ppm})\end{array}$ & $\begin{array}{l}\text { Alkalinity } \\
(\mathrm{mg} / \mathrm{l})\end{array}$ & $\begin{array}{l}\text { LOI } \\
(\%)\end{array}$ & $\begin{array}{l}\text { Chironomid } \\
\text { concentration } \\
\text { (hc/g) }\end{array}$ \\
\hline L01 & 146 & Inundated & A & 2.3 & 2.3 & 16.0 & 4.4 & 17 & 9.3 & 1.6 & 53 & 1,313 \\
\hline L02 & 146 & Inundated & A & 0.2 & 1.6 & 18.7 & 5.2 & 29 & 9.6 & 2.4 & 44 & 1,289 \\
\hline L03 & 146 & Inundated & A & 3.0 & 3.4 & 16.7 & 5.3 & 20 & 8.6 & 0.9 & 32 & 800 \\
\hline L04 & 152 & Isolated & $\mathrm{B}$ & 6.6 & 6.4 & 16.9 & 4.9 & 10 & 9.8 & 0.6 & 60 & 1,701 \\
\hline L05 & 155 & Isolated & B & 0.3 & 1.0 & 19.9 & 5.0 & 8 & 9.0 & 0.2 & 75 & 1,818 \\
\hline L06 & 146 & Isolated & $\mathrm{B}$ & 2.0 & 1.8 & 19.0 & 4.4 & 10 & 9.1 & 0.3 & 69 & 1,847 \\
\hline L07 & 146 & Inundated & $\mathrm{A} / \mathrm{B}$ & 6.3 & 2.0 & 18.1 & 5.8 & 23 & 8.9 & 0.8 & 44 & 1,454 \\
\hline L08 & 146 & Inundated & $\mathrm{A} / \mathrm{B}$ & 2.9 & 1.2 & 18.9 & 6.3 & 31 & 9.2 & 1.0 & 37 & 708 \\
\hline L09 & 146 & Inundated & A & 5.9 & 2.5 & 17.5 & 5.7 & 24 & 7.8 & 1.7 & 31 & 436 \\
\hline L10 & 146 & Inundated & A & 0.1 & 0.8 & 17.9 & 5.6 & 22 & 8.9 & 0.9 & 10 & 85 \\
\hline L11 & 146 & Inundated & A & 0.9 & 0.9 & 17.9 & 5.0 & 10 & 6.7 & 1.0 & 36 & 1,989 \\
\hline L12 & 148 & Inundated & B & 1.9 & 0.9 & 18.7 & 6.2 & 37 & 8.6 & 1.4 & 18 & 111 \\
\hline L13 & 149 & Isolated & B & 2.3 & 5.0 & 18.0 & 4.1 & 7 & 7.5 & 0.0 & 79 & 8,857 \\
\hline L14 & 146 & Inundated & A & 2.7 & 1.6 & 18.0 & 5.4 & 19 & 7.1 & 0.9 & 34 & 816 \\
\hline L15 & 146 & Inundated & A & 2.9 & 2.6 & 18.0 & 5.5 & 19 & 6.9 & 0.6 & 36 & 384 \\
\hline L16 & 152 & Isolated & B & 1.6 & 2.3 & 16.7 & 2.9 & 8 & 5.4 & 0.0 & 83 & 9,840 \\
\hline L17 & 156 & Isolated & B & 1.6 & 3.9 & 16.8 & 3.5 & 10 & 8.0 & 0.0 & 70 & 4,873 \\
\hline L18 & 158 & Isolated & B & 4.5 & 15.9 & 9.7 & 5.3 & 28 & 6.8 & 1.2 & 41 & 880 \\
\hline L19 & 158 & Isolated & B & 0.5 & 3.0 & 15.5 & 5.5 & 29 & 9.3 & 0.6 & 56 & 1523 \\
\hline L20 & 157 & Isolated & B & 1.8 & 4.1 & 13.9 & 5.8 & 35 & 5.6 & 0.8 & 30 & 2,960 \\
\hline L21 & 147 & Inundated & A & 10.7 & 1.6 & 15.6 & 5.2 & 17 & 10.0 & 0.6 & 39 & 915 \\
\hline L22 & 147 & Inundated & A & 3.3 & 3.1 & 15.7 & 5.0 & 21 & 8.9 & 0.4 & 30 & 1,030 \\
\hline L23 & 158 & Isolated & B & 15.8 & 6.9 & 14.4 & 5.4 & 18 & 8.1 & 0.6 & 40 & 1,505 \\
\hline L24 & 152 & Isolated & B & 0.9 & 3.1 & 14.0 & 5.9 & 47 & 7.6 & 0.6 & 60 & 1,895 \\
\hline L25 & 151 & Isolated & B & 0.9 & 3.3 & 10.6 & 4.4 & 33 & 3.1 & 0.9 & 26 & 940 \\
\hline L26 & 153 & Isolated & B & 2.5 & 2.1 & 15.7 & 4.8 & 11 & 8.8 & 0.7 & 70 & 3,243 \\
\hline L27 & 157 & Isolated & B & 0.4 & 5.4 & 11.3 & 5.4 & 63 & 5.2 & 1.3 & 47 & 317 \\
\hline L28 & 163 & Isolated & B & 0.5 & 1.8 & 15.8 & 3.5 & 8 & 8.7 & 0.0 & 77 & 4,538 \\
\hline L29 & 153 & Isolated & B & 3.2 & 1.5 & 14.4 & 6.1 & 41 & 9.7 & 1.5 & 52 & 1,141 \\
\hline L30 & 154 & Isolated & B & 6.7 & 1.7 & 15.3 & 5.9 & 21 & 10.2 & 0.5 & 55 & 1,120 \\
\hline L31 & 152 & Isolated & B & 14.3 & 3.3 & 15.8 & 3.9 & 9 & 8.7 & 0.3 & 59 & 4,109 \\
\hline L32 & 156 & Isolated & B & 0.1 & 1.0 & 17.0 & 4.4 & 44 & 9.3 & 0.5 & 74 & 726 \\
\hline L33 & 156 & Isolated & B & 0.4 & 2.3 & 13.0 & 5.9 & 51 & 10.1 & 1.3 & 27 & 594 \\
\hline Mean & 151 & & & 3.3 & 3.0 & 16.1 & 5.1 & 24 & 8.2 & 0.8 & 48 & 1,993 \\
\hline Minimum & 146 & & & 0.1 & 0.8 & 9.7 & 2.9 & 7 & 3.1 & 0.0 & 9 & 85 \\
\hline Maximum & 163 & & & 15.8 & 15.9 & 19.9 & 6.3 & 63 & 10.2 & 2.4 & 82 & 9,840 \\
\hline
\end{tabular}

Lake numbers refer to lakes indicated in Fig. 1. Vegetation type A indicates a vegetation dominated by sedges, type B a vegetation dominated by pine and birch. A value of 0 refers to concentrations below the detection limit. Minimum, mean and maximum values are presented for each variable (where applicable). Abbreviations include: T water: average temperature of the water column; LOI: loss-on-ignition; hc: head capsules; EC: electric conductivity 
Table 2 Chemical parameters of the 33 lakes in the data set

\begin{tabular}{|c|c|c|c|c|c|c|c|c|c|c|c|c|c|c|c|}
\hline Lake nr & $\begin{array}{l}\text { TOC } \\
(\mathrm{mg} / \mathrm{l})\end{array}$ & $\begin{array}{l}\delta^{18} \mathrm{O} \\
(\% \text { SMOW })\end{array}$ & $\begin{array}{l}\mathrm{Na} \\
(\mathrm{mg} / \mathrm{l})\end{array}$ & $\begin{array}{l}\mathrm{K} \\
(\mathrm{mg} / \mathrm{l})\end{array}$ & $\begin{array}{l}\mathrm{Mg} \\
(\mathrm{mg} / \mathrm{l})\end{array}$ & $\begin{array}{l}\mathrm{Ca} \\
(\mathrm{mg} / \mathrm{l})\end{array}$ & $\begin{array}{l}\mathrm{Fe} \\
(\mathrm{mg} / \mathrm{l})\end{array}$ & $\begin{array}{l}\mathrm{Al} \\
(\mathrm{mg} / \mathrm{l})\end{array}$ & $\begin{array}{l}\mathrm{Mn} \\
(\mathrm{mg} / \mathrm{l})\end{array}$ & $\begin{array}{l}\mathrm{Si} \\
(\mathrm{mg} / \mathrm{l})\end{array}$ & $\begin{array}{l}\text { TP } \\
(\mathrm{mg} / \mathrm{l})\end{array}$ & $\begin{array}{l}\mathrm{Cl} \\
(\mathrm{ppm})\end{array}$ & $\begin{array}{l}\mathrm{NH}_{4} \\
(\mathrm{ppm})\end{array}$ & $\begin{array}{l}\mathrm{PO}_{4} \\
(\mathrm{ppb})\end{array}$ & $\begin{array}{l}\mathrm{SO}_{4} \\
(\mathrm{ppm})\end{array}$ \\
\hline L01 & 5.51 & -8.3 & 1.8 & 0.43 & 0.6 & 1.4 & 0.11 & 0.04 & 0.005 & 0.1 & 0.004 & 1.7 & 0.068 & 5.4 & 1.0 \\
\hline L02 & 4.35 & -11.8 & 1.6 & 0.41 & 1.0 & 2.8 & 0.20 & 0.11 & 0.012 & 2.9 & 0.010 & 1.1 & 0.000 & 4.7 & 2.8 \\
\hline L03 & 5.00 & -9.6 & 1.3 & 0.40 & 0.8 & 1.7 & 0.16 & 0.04 & 0.005 & 0.6 & 0.080 & 0.0 & 0.122 & 20.8 & 1.3 \\
\hline L04 & 4.72 & -8.8 & 2.6 & 0.57 & 0.6 & 2.0 & 0.12 & 0.19 & 0.003 & 0.3 & 0.006 & 1.1 & 0.000 & 3.6 & 1.0 \\
\hline L05 & 5.42 & -7.4 & 0.8 & 0.37 & 0.2 & 0.7 & 0.06 & 0.10 & 0.004 & 0.1 & 0.009 & 1.0 & 0.053 & 10.2 & 1.2 \\
\hline L06 & 3.34 & -6.8 & 0.8 & 0.33 & 0.2 & 0.6 & 0.04 & 0.09 & 0.006 & 0.1 & 0.011 & 0.9 & 0.125 & 21.3 & 2.5 \\
\hline L07 & 4.23 & -10.6 & 1.4 & 0.42 & 1.1 & 1.9 & 0.20 & 0.05 & 0.011 & 0.4 & 0.005 & 1.1 & 0.038 & 3.7 & 1.4 \\
\hline L08 & 4.27 & -10.9 & 0.1 & 0.17 & 0.0 & 0.1 & 0.06 & 0.04 & 0.003 & 0.8 & 0.000 & 1.1 & 0.010 & 202.5 & 2.5 \\
\hline L09 & 4.21 & -10.8 & 1.2 & 0.21 & 1.0 & 1.5 & 0.13 & 0.04 & 0.005 & 0.7 & 0.005 & 0.9 & 0.047 & 3.1 & 2.4 \\
\hline L10 & 5.64 & -9.9 & 1.4 & 0.36 & 1.0 & 1.9 & 0.20 & 0.05 & 0.006 & 0.3 & 0.018 & 1.0 & 0.006 & 7.2 & 1.7 \\
\hline L11 & 5.22 & -8.3 & 0.7 & 0.20 & 0.4 & 1.4 & 0.38 & 0.03 & 0.012 & 0.1 & 0.009 & 0.5 & 0.008 & 2.4 & 0.7 \\
\hline L12 & 5.30 & -9.4 & 1.7 & 0.55 & 1.2 & 4.0 & 0.18 & 0.05 & 0.009 & 1.8 & 0.019 & 1.3 & 0.000 & 4.3 & 2.5 \\
\hline L13 & 1.65 & -6.3 & 0.6 & 0.23 & 0.2 & 0.2 & 0.59 & 0.11 & 0.056 & 0.1 & 0.034 & 0.7 & 0.013 & 3.7 & 1.2 \\
\hline L14 & 5.46 & -8.9 & 1.1 & 0.33 & 0.7 & 1.7 & 0.20 & 0.03 & 0.010 & 0.2 & 0.000 & 0.9 & 0.013 & 31.2 & 1.0 \\
\hline L15 & 5.70 & -8.7 & 1.0 & 0.30 & 0.8 & 1.7 & 0.26 & 0.13 & 0.009 & 0.3 & 0.021 & 0.8 & 0.013 & 37.9 & 1.1 \\
\hline L16 & 3.63 & -6.2 & 0.5 & 0.31 & 0.2 & 0.4 & 0.04 & 0.06 & 0.015 & 0.0 & 0.002 & 0.7 & 0.005 & 4.6 & 1.4 \\
\hline L17 & 6.47 & -6.7 & 0.8 & 0.36 & 0.2 & 0.4 & 0.07 & 0.03 & 0.010 & 0.0 & 0.006 & 1.3 & 0.040 & 4.2 & 1.1 \\
\hline L18 & 3.22 & -11.3 & 0.4 & 0.26 & 0.6 & 0.0 & 0.00 & 0.07 & 0.000 & 1.1 & 0.041 & 1.3 & 0.021 & 4.5 & 4.5 \\
\hline L19 & 3.84 & -11.3 & 1.5 & 0.41 & 1.0 & 2.7 & 0.04 & 0.02 & 0.000 & 0.5 & 0.000 & 1.3 & 0.104 & 4.2 & 4.0 \\
\hline L20 & 5.17 & -11.6 & 1.6 & 0.41 & 1.2 & 2.9 & 0.12 & 0.00 & 0.003 & 2.8 & 0.008 & 1.4 & 0.037 & 4.8 & 3.9 \\
\hline L21 & 7.38 & -9.5 & 1.2 & 0.36 & 0.8 & 1.8 & 0.54 & 0.13 & 0.004 & 0.3 & 0.019 & 1.2 & 0.008 & 9.3 & 0.5 \\
\hline L22 & 7.01 & -9.4 & 1.3 & 0.35 & 0.8 & 1.8 & 0.26 & 0.11 & 0.005 & 0.3 & 0.013 & 1.0 & 0.024 & 3.6 & 0.7 \\
\hline L23 & 6.46 & -10.5 & 1.1 & 0.32 & 0.6 & 1.7 & 0.25 & 0.05 & 0.001 & 0.9 & 0.000 & 1.1 & 0.003 & 3.9 & 1.1 \\
\hline L24 & 2.92 & -10.5 & 0.2 & 0.16 & 0.1 & 1.8 & 0.01 & 0.04 & 0.001 & 1.3 & 0.019 & 2.2 & 0.197 & 11.4 & 24.6 \\
\hline L25 & 8.95 & -14.0 & 1.7 & 0.42 & 1.6 & 3.1 & 0.56 & 0.08 & 0.004 & 4.5 & 0.008 & 1.6 & 0.005 & 2.9 & 0.0 \\
\hline L26 & 7.64 & -7.1 & 1.0 & 0.15 & 0.5 & 0.6 & 0.12 & 0.05 & 0.003 & 0.1 & 0.017 & 0.9 & 0.038 & 3.3 & 1.0 \\
\hline L27 & 4.92 & -13.1 & 2.1 & 0.64 & 2.0 & 4.5 & 0.09 & 0.12 & 0.041 & 3.9 & 0.000 & 1.8 & 0.026 & 3.4 & 4.3 \\
\hline L28 & 6.41 & -7.6 & 0.7 & 0.32 & 0.3 & 0.4 & 0.41 & 0.10 & 0.043 & 0.2 & 0.012 & 0.9 & 0.012 & 3.7 & 1.0 \\
\hline L29 & 5.68 & -9.8 & 2.2 & 0.65 & 1.2 & 3.7 & 0.08 & 0.05 & 0.004 & 0.9 & 0.011 & 2.4 & 0.052 & 3.0 & 16.7 \\
\hline L30 & 5.94 & -8.0 & 1.5 & 0.44 & 0.6 & 1.7 & 0.05 & 0.03 & 0.001 & 1.7 & 0.009 & 1.4 & 0.040 & 3.3 & 2.5 \\
\hline L31 & 3.75 & -6.8 & 0.7 & 0.26 & 0.2 & 0.4 & 0.05 & 0.04 & 0.004 & 0.0 & 0.009 & 0.9 & 0.127 & 5.5 & 1.6 \\
\hline L32 & 5.76 & -5.8 & 1.5 & 0.45 & 1.0 & 4.4 & 0.58 & 0.11 & 0.084 & 0.2 & 0.019 & 8.5 & 0.117 & 3.6 & 4.4 \\
\hline L33 & 1.33 & -14.4 & 1.9 & 0.73 & 1.3 & 5.6 & 0.01 & 0.05 & 0.000 & 4.5 & 0.008 & 1.8 & 0.001 & 4.0 & 4.2 \\
\hline Mean & 5.05 & -9.4 & 1.2 & 0.37 & 0.7 & 1.9 & 0.19 & 0.07 & 0.012 & 1.0 & 0.012 & 1.4 & 0.041 & 13.4 & 3.1 \\
\hline Minimum & 1.33 & -14.4 & 0.1 & 0.15 & 0.0 & 0.0 & 0.00 & 0.02 & 0.000 & 0.0 & 0.000 & 0.5 & 0.000 & 2.4 & 0.0 \\
\hline Maximum & 8.95 & -5.8 & 2.6 & 0.73 & 2.0 & 5.6 & 0.59 & 0.19 & 0.084 & 4.5 & 0.080 & 8.5 & 0.197 & 202.5 & 24.6 \\
\hline
\end{tabular}

Lake numbers refer to lakes indicated in Fig. 1. A value of 0 refers to concentrations below the detection limit. Minimum. mean and maximum values are presented for each variable

The WA-PLS model was developed and implemented using C2 version 1.4.3 (Juggins 2003).

\section{Results}

Taxon richness and chironomid concentrations

The taxon richness (TR) estimated for a count sum of $149 \mathrm{hcs}$ (equivalent to our minimum count sum), ranges between 14 and 43 for the 33 lakes. Using RDA with forward selection, LOI was selected as the environmental variable explaining the most variance in TR $(\lambda=0.59$ of total inertia of $0.90, p=0.001)$. $\mathrm{O}_{2}$ was the second forward selected variable with $p=0.022$, explaining an additional $10 \%$ of the total variance. The relatively strong (linear) correlation $\left(r^{2}=0.58\right)$ between the LOI and TR is plotted in Fig. 2a. Most inundated lakes have a lower LOI than 

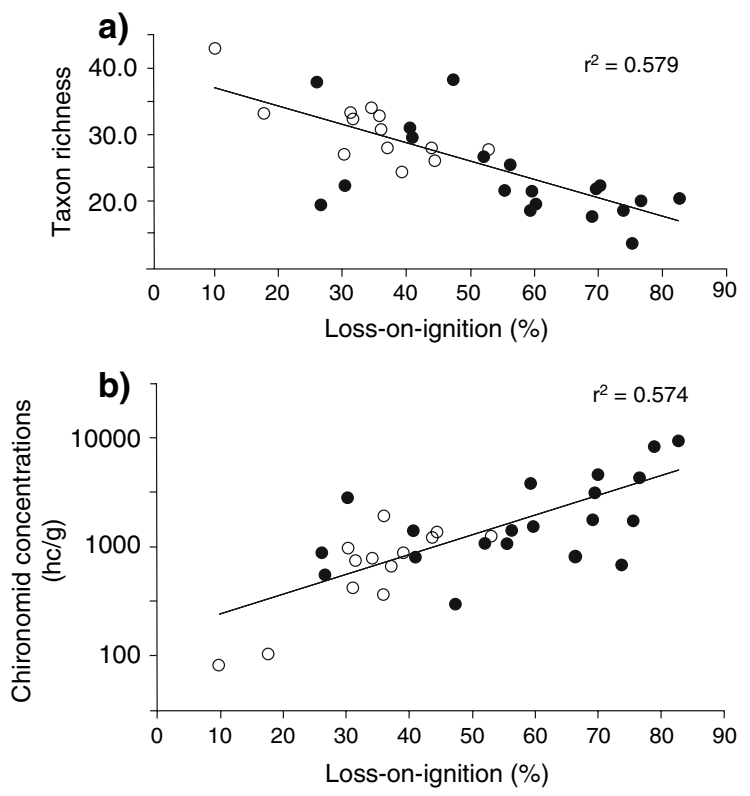

Fig. 2 (a) Taxon richness and (b) chironomid concentrations plotted against loss-on-ignition. Open circles indicate inundated lakes, solid circles isolated lakes; regression lines are linear models

the isolated lakes, but there also seems to be a tendency for the isolated lakes to have a lower TR. The hypothesis that both groups of lakes have statistically different TR values was tested using a $t$-test. The resulting $t=3.56$ and $p=0.0012$ show that the chance of a type I error (false rejection of $H_{0}$ ) is lower than $5 \%$, and $H_{0}$ (=both groups have the same means) is rejected.

A $t$-test performed on the chironomid concentrations (hcs encountered per gram of freeze-dried sediment) of the two groups resulted in a $t=-2.49$, where $t$-critical $(\alpha=5 \%)=2.2$. This indicates that the mean chironomid concentration in the group of isolated lakes is significantly different than that of the inundated lakes. The relationship between the chironomid concentrations of the 33 lakes and the environmental variables was examined using RDA. LOI was selected as the variable with the strongest relationship with chironomid concentrations (explaining $\lambda=0.57$ of total inertia of $0.84, p=0.001$ ). Forward selection showed that $[\mathrm{Cl}]$ had a significant relationship $(p<0.05)$ with the chironomid concentrations, explaining an additional $10 \%$ of the variance in the data. Figure $2 b$ shows the log-transformed chironomid concentration of the individual lakes, plotted against LOI.
Physical and chemical properties of the lakes

PCA was performed on the physical variables, water column chemistry and LOI data presented in Table 1, and the chemical data presented in Table 2. Variables that were excluded from the analysis were chemical variables that showed a large co-variance with other variables retained in the analysis, and the data on nominal/ordinal scale. The variance explained by the first three constructed PCA axes is: $26.3,18.0$ and $14.5 \%$. Figure $3 \mathrm{a}$ shows a biplot of the environmental variables and the sites on the first two axes.

Water chemistry variables are strongly correlated with the first PCA-axis, whereas physical variables of the lake and its catchment dominate the second axis. The third axis (not shown here) shows a strong correlation with cation concentrations. As can be seen in Fig. 3a, the regularly inundated lakes cluster together in the PCA, implying that lakes belonging to this class have a similar physical and chemical environment. The means of the two different classes are similar for the variables that correlate strongly with the first axis, but there is a difference in lakescores on the second axis: the inundated lakes are on the negative side of the axis, the isolated lakes on the positive side. Further analyses show that when "elevation" is omitted from the dataset, this difference in lake-scores on the second axis disappears. Therefore, the lakes in both classes seem to have similar means for most chemical and physical variables, but the larger scatter of PCA axis scores (Fig. 3a) indicates that the variability in values is larger for the isolated group.

\section{Chironomid abundance data}

Correspondence analysis (CA) showed that the isolated lakes and the regularly inundated lakes both cluster together in separate groups when using the chironomid-data as input (Fig. 3b), implying that the chironomid faunas of the two classes of lakes differ. The colder lakes (Lake 23 and Lake 33), and those showing strong thermal stratification and bottomwater anoxia during the fieldwork period (Lake 18, Lake 25 and Lake 27), plot outside of the cluster of isolated lakes. The variance explained on the first two axes plotted in Fig. $3 \mathrm{~b}$ is 18.8 and $11.2 \%$. 
Axis 1
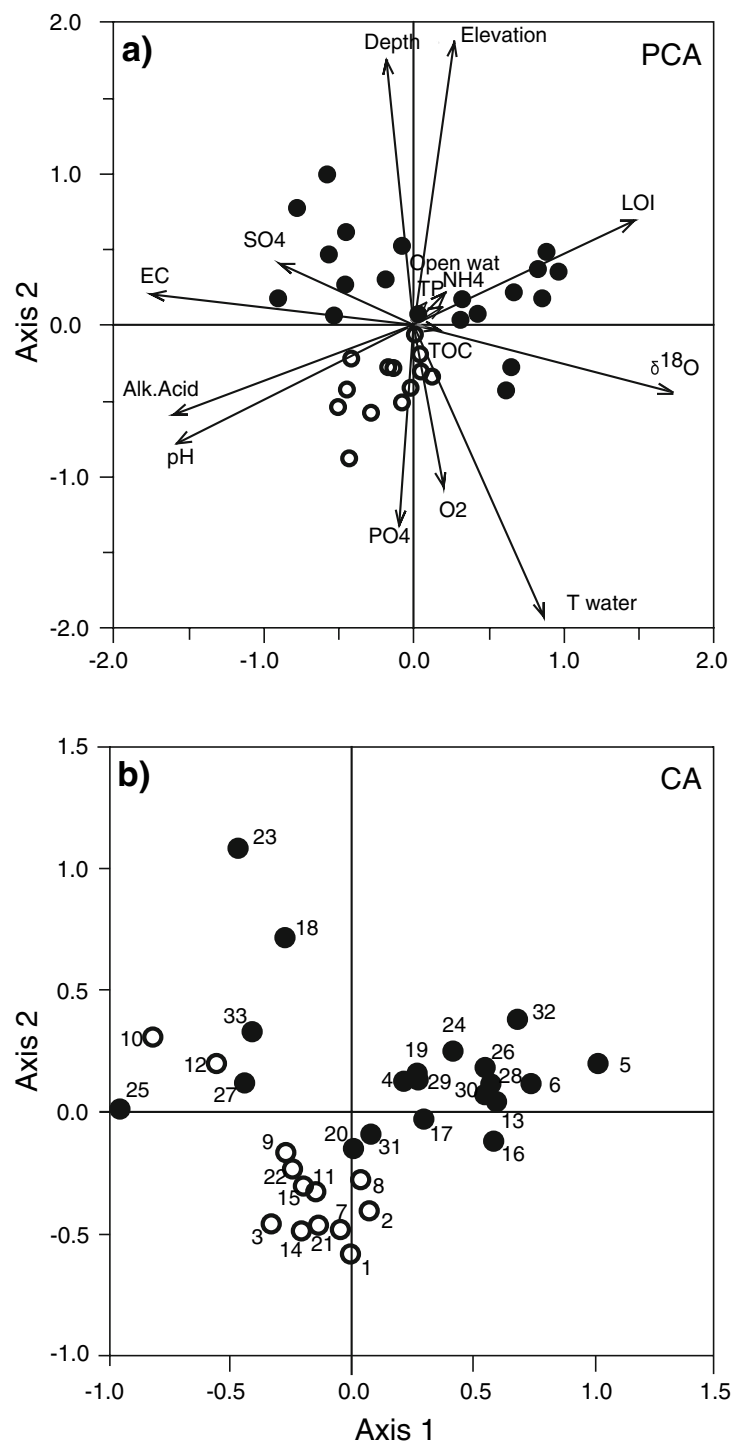

Fig. 3 (a) Principal components analysis (PCA) biplot of selected environmental variables and sites. The variance explained by the first and second axis is 26.3 and $18.0 \%$ respectively. (b) Correspondence analysis (CA) scatter-plot of sites. The variance explained by the first and second axis is 18.8 and $11.2 \%$ respectively. Open circles indicate inundated lakes, solid circles isolated lakes

In an initial series of CCAs with 24 exploratory variables, 13 variables were manually selected as explaining a statistical significant amount of the total inertia $(p<0.05)$. Of these variables, LOI was selected as the variable that is most strongly related to variation in the chironomid abundances $(15.1 \%$;
Table 3). This was followed by $\delta^{18} \mathrm{O}$ (10\%), $\mathrm{Mg}$ $(8.3 \%)$, and elevation $(7.4 \%)$.

A series of CCAs with forward selection was performed to determine the marginal and unique effects of the different environmental variables (Table 3). Again, LOI was selected as the most important explanatory variable, now followed by elevation, $\mathrm{O}_{2}$, TOC, lake depth and electric conductivity (EC). The first axis of a CCA with these 6 variables now explains $16.9 \%$ of the total inertia $(\lambda=0.192$ of total 1.135$)$.

A total of 86 chironomid taxa were identified for the 33 lakes from northern Finland. Figure 4 shows the abundance of selected taxa per lake in inundated and isolated lakes. Several head capsule types have been amalgamated within the taxa Corynoneura spp.

Table 3 Marginal and conditional effects of explanatory variables

\begin{tabular}{|c|c|c|c|c|}
\hline \multirow[t]{2}{*}{ Variable } & \multicolumn{2}{|c|}{ Marginal effects } & \multicolumn{2}{|c|}{ Conditional effects } \\
\hline & $\begin{array}{l}\text { Variance } \\
\text { explained }(\%)\end{array}$ & $P$ & $\begin{array}{l}\text { Variance } \\
\text { explained }(\%)\end{array}$ & $P$ \\
\hline LOI & 15.1 & 0.001 & 15.0 & 0.001 \\
\hline Elevation & 7.4 & 0.002 & 7.0 & 0.001 \\
\hline $\mathrm{O}_{2}$ & 6.2 & 0.008 & 5.3 & 0.001 \\
\hline TOC & 5.5 & 0.017 & 4.4 & 0.003 \\
\hline Depth & 5.7 & 0.019 & 4.4 & 0.004 \\
\hline EC & 7.1 & 0.002 & 4.4 & 0.010 \\
\hline $\mathrm{SO}_{4}$ & 4.9 & 0.059 & & \\
\hline $\mathrm{Ca}$ & 6.1 & 0.008 & & \\
\hline $\mathrm{Mg}$ & 8.3 & 0.001 & & \\
\hline $\mathrm{T}$ water & 6.4 & 0.010 & & \\
\hline $\mathrm{PO}_{4}$ & 3.2 & 0.348 & & \\
\hline Open water & 4.5 & 0.096 & & \\
\hline$\delta^{18} \mathrm{O}$ & 10.0 & 0.001 & & \\
\hline Alk. acid & 7.4 & 0.003 & & \\
\hline K & 3.4 & 0.351 & & \\
\hline $\mathrm{NH}_{4}$ & 4.1 & 0.154 & & \\
\hline $\mathrm{Na}$ & 3.8 & 0.223 & & \\
\hline $\mathrm{pH}$ & 5.6 & 0.023 & & \\
\hline $\mathrm{Cl}$ & 4.2 & 0.196 & & \\
\hline $\mathrm{Si}$ & 6.9 & 0.001 & & \\
\hline $\mathrm{Mn}$ & 3.2 & 0.398 & & \\
\hline $\mathrm{Fe}$ & 3.5 & 0.280 & & \\
\hline $\mathrm{Al}$ & 1.8 & 0.970 & & \\
\hline $\mathrm{TP}$ & 1.9 & 0.904 & & \\
\hline
\end{tabular}

Statistically significant relationships are plotted in bold 


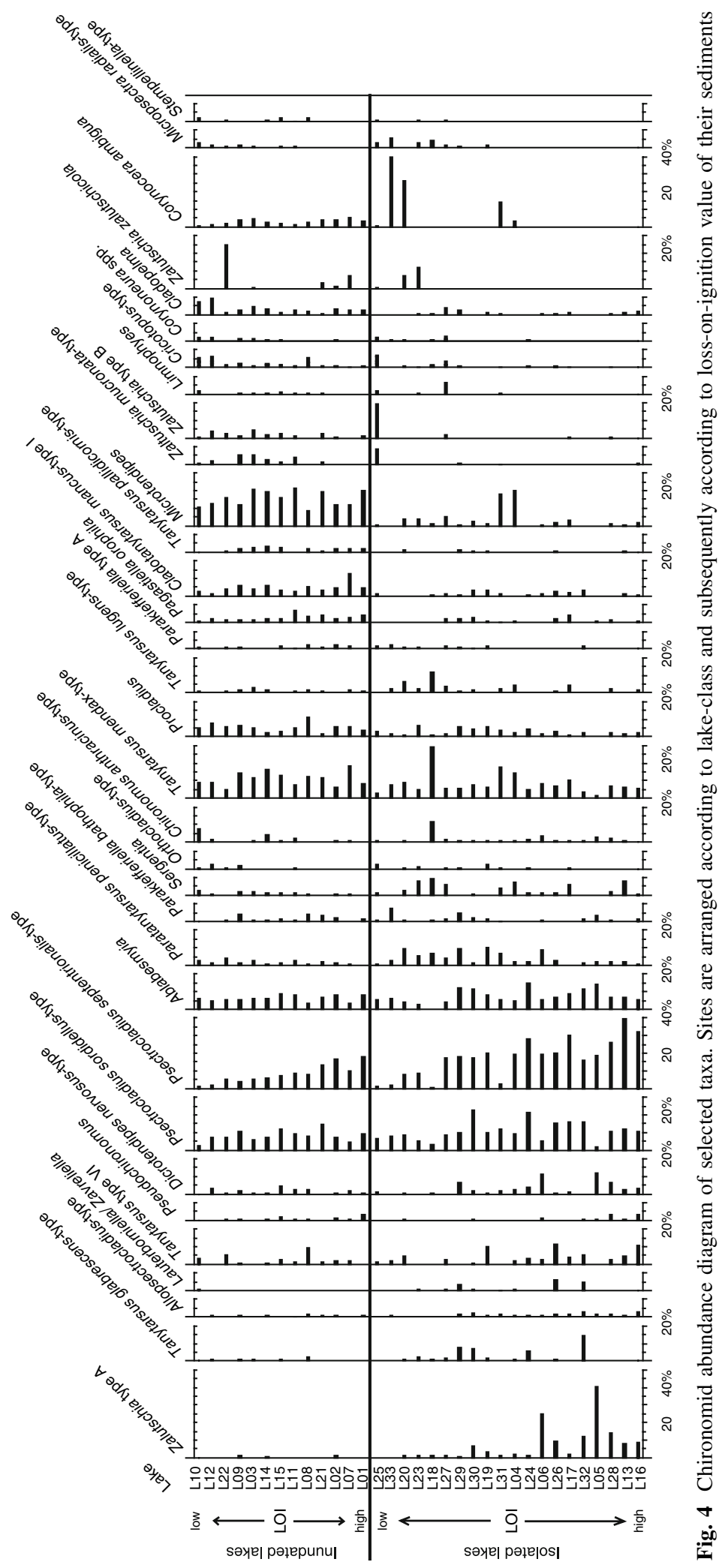


and Cricotopus-type to enhance the readability of the figure.

Although the most abundant taxa all occur in both the inundated and the isolated lakes, there are certain taxa that show a preference for one of the two groups. Cladotanytarsus mancus-type I, Cladopelma, Cricotopus-type, Microtendipes and Tanytarsus pallidicornis-type all show a preference for the regularly inundated lakes, whereas Dicrotendipes nervosustype, Lauterborniella/ Zavreliella, Paratanytarsus penicillatus-type, Sergentia, Tanytarsus type VI and T. glabrescens-type show higher abundances in the isolated lakes. The differences within the genus Zalutschia are also striking: whereas Zalutschia type A almost exclusively occurs in isolated lakes with a high organic matter content of the sediments, the other identified taxa (Zalutschia type B, Z. mucronata-type and Z. zalutschicola) all are restricted to the inundated sites or sites with a low LOI. The different types within the genus Psectrocladius all show a preference for the isolated lakes, but they also feature a strong correlation with LOI: in both classes of lakes we see increasing abundances of e.g., P. septentrionalis-type with increasing LOI (Fig. 4).

Intraregional variability in temperature inferences

The results of applying a chironomid-temperature inference model to our 33-lake dataset are shown in Fig. 5. The inferred temperatures are all around or lower than the measured 30 year average July air temperature for Kaamanen (Drebs et al. 2002), and sample specific errors are $\pm 0.79-0.88^{\circ} \mathrm{C}$. The group of inundated lakes shows less diverse temperature estimates and values closer to the observed temperature than the group of isolated lakes. The standard deviation of the temperature-inferences within the group of inundated lakes is $0.32{ }^{\circ} \mathrm{C}$, and within the group of lakes isolated from riverine influence $0.54^{\circ} \mathrm{C}$. This low variability in inferred temperatures was expected for the group of inundated lakes, as the variation in the chironomid-abundance data was also low in this group (Fig. 3b). Lake 33 can be considered as an outlier, as it has a reconstructed temperature of $10.6^{\circ} \mathrm{C}$, approximately $1^{\circ} \mathrm{C}$ lower than the second lowest reconstructed value.

\section{Discussion}

Inundated lakes versus isolated sites: environment

Thomaz et al. (2007) state that river floods result in the homogenization of aquatic habitats on the floodplain. An increased connectivity between the river course and the floodplain will enhance the exchange of water, sediments, minerals and organisms. During periods of low water, the heterogeneity of habitats on a floodplain may be increased through (amongst others) local water inputs from tributaries and ground water seepage (Thomaz et al. 2007). In our dataset, it is clear that the chemistry of the different lakes within the group of floodplain lakes is very uniform. In the PCA analysis (Fig. 3a), the lakes of the inundated class all cluster close together, and the variation in
Fig. 5 Chironomidinferred mean July air temperature estimates in relation to the observed temperature for the Kaamanen region (horizontal line; Drebs et al. 2002). The sample specific error of prediction was determined by bootstrap cross-validation (999 cycles; Birks et al. 1990)

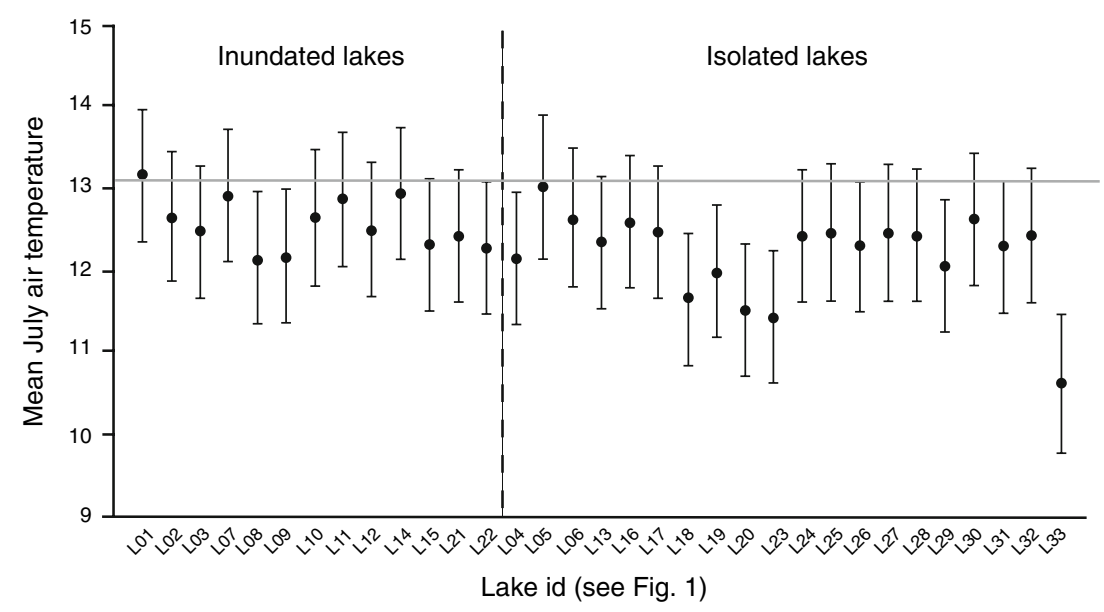


scores on both the first and the second axis is low, implying a low within-group variability in environmental conditions. The lakes that are isolated from riverine influence are plotted in a separate group in the PCA diagram (Fig. 3a). The scores of the lakes on the first axis are similar to those of the inundated class, but the variability in scores is higher, suggesting a higher variation in water chemistry. This is consistent with the expected higher variability due to the more diverse local processes at the isolated sites. The scores on the second axis differ between the two groups, which can be mainly attributed to floodplain characteristics: first, all lakes in the inundated class have the same elevation, as they are situated closely together on the same floodplain. Second, most of these lakes are shallow, as deep lakes on a floodplain will be preferentially filled in. Thirdly, other environmental variables that are correlated to the second axis, e.g., $\mathrm{O}_{2}$, are for some lakes related to depth as well (e.g., bottom water anoxia in deep, stratified lakes with a small area/wind fetch).

This implies that there is a tendency for the floodplain lakes to have similar habitats available for chironomids and other aquatic macrofauna, and that the variability in environmental conditions is higher in lakes isolated from riverine influence.

Inundated lakes versus isolated sites: chironomid fauna

In western Finnish Lapland, the chironomid taxon richness is most strongly correlated with alkalinity (Nyman et al. 2005), which is usually directly connected to weathering intensity of catchment bedrock. In their study, Nyman et al. (2005) assessed chironomid assemblages over a wide range of alkalinity values, whereas the range in alkalinity is limited in our dataset. The variation in TR in our dataset is best explained by LOI and the TR is significantly different in the two lake classes. The floodplain lakes, that on average have a low LOI, are situated at an ecotonal boundary between lotic and lentic habitats, which could result in a more diverse fauna and also a higher TR in this class.

The positive correlation between LOI and the concentration of chironomid remains might be the result of higher (inorganic) sedimentation rates in the regularly inundated lakes as a result of the regular flooding of the lakes. This would result in a lower chironomid concentration per weight, and the correlation between LOI and the concentration of chironomid remains would then be directly related to floodplain processes. It is also possible that the more organic-rich sediments that are present in the lakes that are isolated from riverine influence provide for more food or suitable habitats for a wider range of chironomid taxa, and are possibly characterized by a higher chironomid production.

In all Fennoscandian datasets that describe the distribution of chironomid assemblages in lake surface sediments (e.g., Larocque et al. 2001; Nyman et al. 2005), LOI has been reported as a strong explanatory variable for the differences in relative chironomid abundance. However, in these datasets, LOI is correlated with summer temperatures, and the datasets have been designed to cover a large summer temperature gradient. Therefore, LOI also covers a large range of values. A Canadian chironomidtemperature calibration dataset, where the LOI-range is smaller (Walker et al. 1991), shows that the explanatory power of LOI is much lower than in the Fennoscandian datasets. In the results presented here, the LOI-range is large despite the similar local climatic circumstances; the large range of LOI is probably the result of the riverine input of clastic material in the floodplain lakes, and diverse local settings in the isolated lakes.

Many chironomid larvae live as infauna in the lake sediment. The organic matter content of these sediments may affect the ability of different chironomid taxa to burrow into the sediments (Lindegaard 1997; Larocque et al. 2001). Furthermore, a number of chironomids are detritus feeders (Pinder 1986; Korhola et al. 2000) and substrate composition may affect the success of this feeding strategy. Thus, the organic matter content of lake sediments can have a direct impact on the chironomid populations (Bigler et al. 2006). We can also see this in Fig. 4, where a number of species show a preference for either low or high organic content of the lake sediments. Therefore, it is likely that the variations in relative chironomid abundances are directly related to sedimentary organic matter content and thereby (indirectly) driven by river inundations.

Interestingly, chironomid assemblages in the studied lakes contained only very few truly rheophilous chironomid taxa (as described by e.g., Moller Pillot 
(1990) and Moog (1995)). A number of the chironomid taxa shown in Fig. 4 are commonly found in streams and rivers, e.g., Orthocladius-type, Cricotopus-type, and Limnophyes (e.g., Wiederholm 1983). However, all of these taxa can also live in shallow lakes, and the remains of these taxa are at most slightly more common in inundated lakes than in isolated lake basins. This suggests that the majority of chironomid head capsules found even in the regularly inundated lakes were produced in the lakes rather than transported there from running water habitats.

Gandouin et al. (2006) showed that chironomidassemblages encountered in lotic and lentic habitats in southern France could be used to qualitatively infer past changes in palaeodischarge and floods. In our study, we did not encounter chironomids restricted to running water habitats, as most of the abundant taxa are known to occur in a range of different habitats. Therefore, no inferences of e.g., the connectivity of the floodplain lakes with the main river channel can be made based on the chironomid assemblages.

Implication of river inundations for chironomidbased temperature inference

The chironomid-inferred July air temperatures are all similar to or slightly lower than the observed modern temperatures in the Kaamanen region. The variability in the chironomid-inferred temperatures is surprisingly low, considering the different environmental settings of the lakes incorporated in the dataset. Ground water influx in the inundated lakes probably buffered the water-temperature differences between the different lakes on the floodplain.

Most weighted averaging-based transfer functions suffer from the "edge-effect" where inferred temperatures at the edge of the environmental gradient of interest tend to be biased towards mean values (Birks 1998; Brooks and Birks 2001). Since the temperatures reconstructed for our study lakes are towards the warmer side of the values in our calibration set, it is not unexpected that our reconstructed temperatures are slightly lower than the measured temperature. Other differences between our study sites and the lakes from northwestern Finland on which the applied transfer function is based, like the clearly more acidic lakes in the region of Kaamanen (average $\mathrm{pH}$ of 5.1 in our study versus $\mathrm{pH}=7.0$ in the western
Finnish training set (Olander et al. 1999)) might also have induced differences in the reconstructed temperatures.

The reconstructed temperature for Lake 33 is distinctly lower than the observed temperature, even when the sample specific errors are taken into account. Lake 33 had a water-temperature that was $4^{\circ} \mathrm{C}$ lower than a lake that was only situated $300 \mathrm{~m}$ away (Lake 32; sampled on the same day) and can therefore be considered as an outlier in our data set.

The most important conclusion for this project, which can be drawn from Fig. 5, is that there is little difference in the chironomid-inferred temperatures between the two lake classes. This implies that, according to our results, fossil chironomid records derived from floodplain sediments can be used to reconstruct summer temperatures, as reliable as records based on chironomid assemblages from lakes unaffected by riverine influence. This seems to be the case even if the applied chironomid-temperature inference model is developed based on sediments from lakes isolated from riverine influence and annual flooding.

\section{Conclusions}

In order to investigate the potential influence of river inundations on fossil chironomid assemblages, sediments and water-samples from 13 regularly inundated lakes and 20 lakes isolated from riverine influence where analysed and compared. The main conclusions that can be drawn from this study are the following:

(1) Taxon richness is significantly higher and the chironomid concentration significantly lower in inundated lakes, and there are several taxa that occur preferentially (although not exclusively) in one of the two groups. However, the chironomid fauna shows only comparatively minor differences between the two groups of lakes.

(2) Organic matter content of the sediment (as LOI) is the environmental variable that best explains the variation in taxon richness, chironomid concentrations, and in the relative chironomid abundance data between the different studied lakes.

(3) Although there are differences in the chironomid fauna of the individual lakes, chironomid- 
inferred temperatures based on a modern calibration set and transfer function from northwest Finland are relatively constant. All reconstructed temperatures are similar to or slightly lower than the measured temperature for the Kaamanen region, possibly related to the edge effect in the applied transfer function. However, on average there is no difference in the temperature inferences for lakes situated on the floodplain versus those isolated from riverine influence.

The results suggest that floodplain sediments are a useful alternative for chironomid-based temperature reconstruction in regions and for time-windows for which lacustrine records unaffected by riverine influence are rare.

Acknowledgements The experience and help of R. Hall, A. Kaakinen and V.P. Salonen during the preparation of this project is very much appreciated. P. Karlsson and P. Räinä provided access to unpublished data, for which we are grateful. We would like to thank M. Groen, F. Backer, W. Koot, W. Hoek and T. van Druten for their technical support, and D. Groot, G. Venhuizen and L. Bohncke for their assistance during the fieldwork. The research project of S.E. is supported by the Council of Earth and Life Sciences of the Netherlands Organization for Scientific Research (grant-no 813.02.004). E. Gandouin and an anonymous reviewer are thanked for their useful suggestions. This is a Netherlands Research School of Sedimentary Geology publication 20070702.

\section{References}

Armitage PD (1995) The behaviour and ecology of adults. In: Armitage PD, Cranston PS, Pinder LC (eds) The Chironomidae: the biology and ecology of nonbiting midges. Chapman and Hall, London, pp 194-224

Bigler C, Larocque I, Peglar SM, Birks HJB, Hall RI (2002) Quantitative multiproxy assessment of long-term patterns of Holocene environmental change from a small lake near Abisko, northern Sweden. The Holocene 12:481-496

Bigler C, Heiri O, Krskova R, Lotter AF, Sturm M (2006) Distribution of diatoms, chironomids and cladocera in surface sediments of thirty mountain lakes in south-eastern Switzerland. Aquatic Sciences 68:154-171

Birks HJB (1998) Numerical tools in palaeolimnology-progress, potentialities, and problems. J Paleolimnol 20:307332

Birks HJB, Line JM (1992) The use of rarefaction analysis for estimating palynologival richness from Quaternary pollen-analytical data. The Holocene 2:1-10

Birks HJB, Line JM, Juggins S, Stevenson AC, Ter Braak CJF (1990) Diatoms and $\mathrm{pH}$ reconstruction. Philos Trans R Soc Lond B 327:263-278
Bos JAA, Bohncke SJP, Kasse C, Vandenberghe J (2001) Vegetation and climate during the Weichselian Early Glacial and Pleniglacial in the Niederlausitz, eastern Germany-macrofossil and pollen evidence. J Quat Sci 16:269-289

Brooks SJ (2006) Fossil midges (Diptera: Chironomidae) as palaeoclimatic indicators for the Eurasian region. Quat Sci Rev 25:1894-1910

Brooks SJ, Birks HJB (2001) Chironomid-inferred air temperatures from Lateglacial and Holocene sites in northwest Europe: progress and problems. Quat Sci Rev 20:1723-1741

Brooks SJ, Bennion H, Birks HJB (2001) Tracing lake trophic history with a chironomid-total phosphorus inference model. Freshw Biol 46:513-533

Brooks SJ, Langdon PG, Heiri O (2007) The identification and use of Palaearctic Chironomidae larvae in palaeoecology. Quaternary Research Association Technical Guide 10, $276 \mathrm{pp}$

Cranston PS (1995) Systematics. In: Armitage PD, Cranston PS, Pinder LC (eds) The Chironomidae: the biology and ecology of nonbiting midges. Chapman and Hall, London, pp 31-52

Drebs A, Nordlund A, Karlsson P, Helminen J, Rissanen P (2002) Climatological statistics of Finland 1971-2000. Finnish Meteorological Institute, Helsinki, 99 pp

Eggermont H, Heiri O, Verschuren D (2006) Fossil Chironomidae (Insecta:Diptera) as quantitative indicators of past salinity in African Lakes. Quat Sci Rev 25:19661994

Gandouin E, Franquet E, Van Vliet-Lanoë B (2005) Chironomids (Diptera) in river floodplains: their status and potential use for palaeoenvironmental reconstruction purposes. Archiv Hydrobiol 162:511-534

Gandouin E, Maasri A, van Vliet-Lanoë B, Franquet F (2006) Chironomid (Insecta: Diptera) assemblages from a gradient of lotic and lentic waterbodies in river floodplains of France: a methodological tool for paleoecological applications. J Paleolimnol 35:149-166

Gandouin E, Ponel P, Franquet E, Van Vliet-Lanoë B, Andrieu-Ponel V, Keen DH, Brulhet J, Brocandel M (2007) Chironomid responses (Insect: Diptera) to Younger Dryas and Holocene environmental changes in a river floodplain from northern France (St-Momelin, St-Omer basin). The Holocene 17:1-18

Grimm EC (1991-2004) TILIA, TILA.GRAPH, and TGView. Illinois State Museum, Research and Collections Center, Springfield, USA, http://demeter.museum.state.il.us/pub/ grimm/

Heegaard E, Lotter AF, Birks HJB (2006) Aquatic biota and the detection of climate change: are there consistent aquatic ecotones? J Paleolimnol 35:507-518

Heinrichs ML, Walker IR (2006) Fossil midges and palaeosalinity: potential as indicators of hydrological balance and sea-level change. Quat Sci Rev 25:1948-1965

Heiri O, Ekrem T, Willassen E (2004) Larval head capsules of European Micropsectra, ParaTanytarsus and Tanytarsus (Diptera: Chironomidae: Tanytarsini). Version 1.0. http://www.bio.uu.nl/ palaeo/Chironomids/Tanytarsini/ intro.htm 
Heiri O, Lotter AF (2005) Holocene and Late glacial summer temperature reconstruction in the Swiss Alps based on fossil assemblages of aquatic organisms: a review. Boreas 34:506-516

Hill MO, Gauch HG (1980) Detrended correspondence analysis: an improved ordination technique. Vegetation 42:47-58

Juggins S (2003) C2 User guide. Software for ecological and palaeoecological data analysis and visualisation. University of Newcastle, Newcastle upon Tyne, UK

Kasse C, Vandenberghe J, Van Huissteden J, Bohncke SJP, Bos JAA (2003) Sensitivity of Weichselian fluvial systems to climate change (Nochten mine, eastern Germany). Quat Sci Rev 22:2141-2156

Korhola A, Olander H, Blom T (2000) Cladoceran and chironomid assemblages as quantitative indicators of water depth in subarctic Fennoscandian lakes. J Paleolimnol 24:43-54

Korhola A, Vasko K, Toivonen HTT, Olander H (2002) Holocene temperature changes in northern Fennoscandia reconstructed from Chironomids using Bayesian modelling. Quat Sci Rev 21:1841-1860

Larocque I, Hall RI, Grahn E (2001) Chironomids as indicators of climate change: a 100-lake training set from a subarctic region of northern Sweden (Lapland). J Paleolimnol 26:307-322

Lepš J, Šmilauer P (2003) Multivariate Analysis of Ecological Data using CANOCO. University Press, Cambridge

Lindegaard C (1997) Diptera Chironomidae, non-biting midges. In: Nilsson A (ed) Aquatic insects of North Europe, vol 2, Odonata - Diptera. Apollo Books, Stenstrup, 440 pp

Lotter AF, Birks HJB, Hofmann W, Marchetto A (1998) Modern diatom, cladodera, chironomid, and chrysophyte cyst assemblages as quantitative indicators for the reconstruction of past environmental conditions in the Alps. II. Nutrients. J Paleolimnol 19:443-463

Mol J (1997) Fluvial response to Weichselian climate change in the Niederlausitz (Germany). J Quat Sci 12:43-60

Moller Pillot HKM (1990) De larven der nederlandse Chironomidae (Diptera) Deel C: Autoekologie en verspreiding. Nederlandse Faunistische Mededelingen 1C, 87 pp

Moog O (1995) Fauna Aquatica austriaca. Abteilung für Hydrobiologie, Fischereiwirtschaft and Aquakultur der Universität für Bodenkultur, Wien

Nyman M (2007) Distribution of non-biting midges (Diptera, Chironomidae) in subarctic lakes of Finnish Lapland - applications in lake classification and palaeolimnology. Kilpisjärvi Notes 20

Nyman M, Korhola A, Brooks SJ (2005) The distribution and diversity of Chironomidae (Insecta: Diptera) in western Finnish Lapland, with special emphasis on shallow lakes. Global Ecol Biogeogr 14:137-153

Olander H, Birks HJB, Korhola A, Blom T (1999) An expanded calibration model for inferring lakewater and air temperatures from fossil chironomid assemblages in northern Fennoscandia. The Holocene 9:279-294

Pinder LCV (1986) Biology of freshwater Chironomidae. Ann Rev Entomol 31:1-23

Renberg I (1991) The HON-Kajak sediment corer. J Paleolimnol 6:161-170

Sæther OA (1976) Revision of Hydrobaenus Trissocladius Zalutschia Paratrissocladius and some related genera (Diptera: Chironomidae). J Fish Res Board Can 195: 1-287

Schmid PE (1993) A key to the larval Chironomidae and their instars from Austrian danube region streams and rivers with particular reference to a numerical taxonomic approach. Part I. Diamesinae, Prodiamesinae and Orthocladiinae. Wasser und Abwasser Supplement 3/93, 514 pp

Ter Braak CJF, Looman CWN (1994) Biplots in reduced-rank regression. Biometr J 36:983-1003

Thomaz SM, Bini LM, Bozelli RL (2007) Floods increase similarity among aquatic habitats in river-floodplain systems. Hydrobiologia 579:1-13

Vasko K, Toivonen HTT, Korhola A (2000) A Bayesian multinomial Gaussian response model for organism-based environmental reconstruction. J Paleolimnol 24:243-250

Velle G, Brooks SJ, Birks HJB, Willassen E (2005) Chironomids as a tool for inferring Holocene climate: an assessment based on six sites in southern Scandinavia. Quat Sci Rev 24:1429-1462

Walker IR, Cwynar LC (2006) Midges and palaeotemperature reconstruction-the North American experience. Quat Sci Rev 25:1911-1925

Walker IR, Smol JP, Engstrom DR, Birks HJB (1991) An assessment of Chironomidae as quantitative indicators of past climatic change. Can J Fish Aquat Sci 48:975-987

Wiederholm T (1983) Chironomidae of the Holarctic region. Keys and diagnoses. Part I. Larvae. Entomol Scand 19: $1-457$ 